\title{
Understanding the market dynamics of entrepreneurial networks
}

\author{
Desmond Ng \\ Texas A\&M University, Department of Agricultural Economics, College Station, 77845, Texas, USA; dng@ag.tamu.edu
}

\begin{abstract}
Austrian economic explanations of market processes have gained considerable attention by management researchers. A central tenet of the Austrian school is that non-equilibrium market processes are primarily attributed to the subjective behaviors of entrepreneurs. Yet, human actions are not only determined by entrepreneur's unique preferences and experiences, but they are also determined by the actions of connected others. As a result, subjective explanations of market processes are extended to account for the social relationships of human action. A conceptual model that underscores the social networks of subjective and alert entrepreneurs was developed and examined in an agent based-simulation setting. The contributions and implications of this study are also discussed.
\end{abstract}

Keywords: Austrian entrepreneurship, social networks, agent based simulation

\section{Introduction}

\section{'Nothing endures but change' (Laertius)}

Modern markets of the $21^{\text {st }}$ century have been increasingly described in dynamic and unpredictable terms (D'Aveni, 1994; Farjoun, 2002; Jacobson, 1992; Potts, 2001). Technological advancements in the telecommunications, internet, semi-conductor, consumer electronics, pharmaceuticals and life sciences industries have been associated with the complex and rapidly evolving nature of modern markets. Such dynamic changes are particularly evident in the internet search market. Despite being on Fortune's 100 fastest growing company list in 2005, Yahoo's success and growth has rapidly stalled. From 2005, Yahoo's market share and stock value have been quickly outpaced by Google's exceptional growth. More recently, Yahoo has been the subject of an acquisition target by Microsoft. As such dynamic market environments can quickly lead to the reversal of a firm's fortunes (D'Aveni, 1994), there has been a renewed interest amongst management researchers to understand market processes and their underlying causes (Farjoun, 2002; Potts, 2001).

Management researchers have increasingly turned their attention to Austrian economic explanations of market processes (e.g. Jacobson, 1992). According to Austrian economics, market processes are driven by the subjective nature of 'human action' (Von Mises, 1949). Subjectivism generates non-equilibrium processes because differences in an entrepreneur's interpretations, beliefs, and expectations lead to inconsistent / incompatible behaviors that inhibit the coordination and equilibration of market activities (Hayek, 1978; Kirzner, 1997, 2000; O'Driscoll and Rizzo, 1985). Yet, despite a common agreement on the primacy of subjectivism in explaining market processes, there remains much debate amongst Austrian economists on whether markets tend to move towards (Hayek, 1978; Kirzner, 1997, 2000) or away from market equilibrating outcomes (e.g. Lachmann, 1976, 1977, 1986). For instance, according to Lachmann (1976, 1977), subjectivism celebrates an entrepreneur's 'creative imaginations' and the 'spontaneity of human choice'. Such human agency introduces to the market a continued source of 'novelty' and 'surprise' that render the market into a state of constant change or disequilibrium (e.g. Lachmann, 1986; Lewis and Runde, 2007). Yet, according to Hayek (1978) and Kirzner (1997), such a disequilibrium process gives rise to the existence of entrepreneurial rents, such as arbitrage opportunities. Entrepreneurs in competing for such rents provide a corrective force that 'nudges' the market towards an equilibrium outcome (Hayek, 1978; Kirzner, 1997).

Such conflicting explanations of the market process strike at one of the 'oldest challenges' facing social theorists; a problem of how to explain the disequilibrium tendencies that arise from subjective human action while, yet still be able to explain the equilibrative tendencies of socioeconomic order (Lewis and Runde, 2007). Lewis and Runde (2007) contend the disordering / ordering tendencies of the market can be explained by the recursive relationships of human agency and social structure. For instance, by providing access to new experiences and resources, 'diverse networks' (Burt, 1992; Granovetter, 1973; Ng, 2004; Perry-Smith and Shalley, 2003; Reagans and Zuckerman, 2001) enable the entrepreneur to draw on their subjective imaginations to 'create' new innovations that destabilize existing market orders. Yet, an individual's subjective actions can also be constrained by choices that are consistent with 
its collective (Brass et al., 2005; Coleman, 1988; Granovetter, 1985; Reagans and Zuckerman, 2001). For instance, an individual's conformance to 'institutional norms' can lead to orderly market outcomes (e.g. DiMaggio and Powell, 1983). As a result, an entrepreneur's social relationships can accentuate as well as constrain the subjective nature of human action in which such influences can lead to both disequilibrating and equilibrating market outcomes.

However, with the possible exception of O'Driscoll and Rizzo (1985), these social relationships have been generally overshadowed by the 'subjective' focus of the Austrian school. The objective of this study is to extend this subjective orientation by providing greater considerations for the recursive relationships of human agency and social structure. In essence, such an objective is to extend the methodological individualistic premise of the Austrian school to account for the diverse and closed network relationships of subjective human action. This involves developing a conceptual model that draws upon the concepts of subjective and alert entrepreneurship with the concepts of 'closed and diverse' networks to explain the ordering and disordering tendencies of markets.

To develop this conceptual model, the subjective and alert foundations of Austrian entrepreneurship are first discussed. These entrepreneurial foundations are then discussed within the larger context of closed and diverse networks. To examine the dynamic behaviors of these networks, an agent based simulation model is then introduced. As Austrian economists have been criticized for their lack of empirical methods (Lewis and Runde, 2007), this agent based model is proposed as one method that can be used to examine the Austrian market process. This study's contributions and implications to management are then discussed.

\section{Conceptual foundations}

\section{Alert and subjective entrepreneurship}

According to the subjective theme of the Austrian school, subjectivism reflects a basic affirmation for 'the autonomy of the human mind' (Kirzner, 2000: 50). Subjectivism underscores the recognition that markets are not driven by 'objective' physical realities, such as the scarcity of resources, production technologies, population demographics and such. But rather, markets are fundamentally the expression of individualized human preferences, expectations and choices. With subjectivism, an entrepreneur's interpretations, mental beliefs, knowledge and expectations not only differ from those of others, but subjectivity also introduces 'genuine' or 'stochastic' choices (Lachmann, 1986; Lewis and Runde, 2007; Von Mises, 1949). Such choice is reflected by a purposeful 'plan' that involves a means-end relationship
(Lachmann, 1977, 1986). Specifically, in drawing on an entrepreneur's subjective imaginations, a plan involves developing a set of resources combinations (i.e. means) for the pursuit of yet to be realized profits (i.e. ends). Such a subjective premise gives rise to non-equilibrium market outcomes (Kirzner, 1997; Lachmann, 1977, 1986; Lewis and Runde, 2007). Non-equilibrium outcomes arise when individuals have different beliefs of the future (Kirzner, 1997; Lewis and Runde, 2007). As differences in an entrepreneur's interpretations, beliefs, and expectations lead to differences in 'plans' or actions, each individual plan is, therefore, inconsistent or mutually incompatible with those of others. This incompatibility is inconsistent with an equilibrium outcome because an equilibrium outcome is dependent on the condition that each person's plan is mutually consistent or compatible with the plans of countless other people (Kirzner, 1997; Lachmann, 1986; O'Driscoll and Rizzo, 1985). In fact, from a general equilibrium framework, Kirzner (1997: 63) notes that the fulfillment of equilibrium outcome requires that:

'markets consist of successfully maximizing agents whose decisions are held to fit in together perfectly, in the sense that each maximizing decision being made correctly anticipates, in effect, at least all, all other maximizing decision being made simultaneously'. Yet, subjectivism, especially of the variant proposed by Lachmann $(1977,1986)$, celebrates the 'spontaneous acts of creative human imagination' (Lewis and Runde, 2007: 171). Due to such creative imaginations, people will have wildly divergent beliefs and expectations to which lead to different and thus inconsistent plan choices (Lachmann, 1986; Lewis and Runde, 2007). Such inconsistencies not only inhibit the coordination and thus equilibration of the market, but such creative imaginations also interject into the market a continued source of novelty. For instance, a series of creative imaginary efforts or novel plans can lead to a sequence of Schumpeterian like innovations that continually destabilizes a market's existing order. Furthermore, with the passage of time, new knowledge is attained (Lachmann, 1977, 1986). As new knowledge is acquired, this changes an individual's expectations and plans which renders the coordination with others' plans difficult because, with the passage of time, the experiences and plans of others have also changed (Lachmann, 1977; Lewis and Runde, 2007; O'Driscoll and Rizzo, 1985). Lachmann (1977, 1987), thus, contends there is no assurance that the market will ever move in the direction of an equilibrium outcome. Instead, the market is in a state of continued disequilibrium and is to be understood as 'an ongoing process, impelled by the diversity of aims and resources and divergence of expectations, everchanging in a world of unexpected change' (Lachmann, 1986: 24-25). 
Such explanations of market disorder have been tempered by more moderate or orderly explanations of market processes. Based on Hayek's (1978) competitive discovery process, Kirzner (1997) contends subjectivism is the basis for entrepreneurial 'alertness' to which provides a corrective force to 'nudge' the market towards equilibrium (Kirzner, 1997: 70). Alertness refers to 'an attitude of receptiveness to available (but hitherto overlooked) opportunities' (Kirzner, 1997: 72). Alertness involves the discovery of profit opportunities from correcting or revising upon earlier subjective mistakes or errors (Kirzner, 2000). Specifically, Hayek (1978), Kirzner $(1997,2000)$ and Sabooglu and Langlois (2001) contend that since subjective entrepreneurs make decisions based on their unique interpretations, beliefs, and expectations, subjective actions (i.e. plans) are vulnerable to 'errors' and thus some actions will inevitably fail. For instance, an individual's subjective resource decisions are prone to 'errors' in an individual's estimation of their productive contributions (Lachmann, 1977). Such error or ignorance provides opportunities for other 'alert' entrepreneurs to correct for such estimates by choosing an allocation of resources that more closely reflect their productive contributions. As a result, through the corrective influences of alertness, the removal of such errors renders markets to have a tendency to move towards rather than away market from equilibrating outcomes. As Kirzner (1997: 62) notes,

'The dynamic competitive process of entrepreneurial discovery (which is the driving element in this Austrian approach) is one in which is seen as tending systematically toward, rather than away from, the path of equilibrium'.

\section{Collective learning processes and closed and diverse networks}

Since the non-equilibrium tendencies of a market are dependent on the extent to which subjective plans are coordinated or are mutually consistent with those of others (Hayek, 1978; Kirzner, 1997; 2000; Lachmann, 1977, 1986; Lewis and Runde, 2007; O'Driscoll and Rizzo, 1985), such coordination can be explained by the concepts of closed and diverse networks. The concepts of closed and diverse networks are argued to yield different coordinating outcomes and thus directly impact the ordering / disordering tendencies of the market.

Closed networks. According to Coleman (1988), 'closed networks' ${ }^{1}$ consists of cohesive and frequent social

\footnotetext{
${ }^{1}$ Readers should note the concepts of closed and diverse network exhibit similarly properties to Granovetter's (1985) strength of tie concept (see Burt, 1992)
}

interactions among similar knowledge individuals. As a closed network renders each individual to be directly and / or indirectly connected to similar others, interactions with such closed network members lead to the recombination of similar plan experiences. This contributes to a convergence of behaviors and plans towards increasingly homogeneous outcomes. As the behavior and plans of each individual are increasingly similar, members can better anticipate the actions of each other to which enables individuals to better coordinate their actions towards the specialization of tasks (Coleman, 1988; Gargiulo and Benassi, 2000). Specifically, the specialization of tasks stems from individuals leveraging the established yet similar experiences of its collective (Coleman, 1988). By drawing on these collective experiences, an individual promotes the diffusion of 'social rules or norms' to which breeds a social consensus and conformity to the experiences of the closed network (Coleman, 1988; Gargiulo and Benassi, 2000). With such social consensus, closed network members develop an increasing consistency in their expectations. This enables members to further anticipate each others actions and thus further coordinate the collective's actions towards the specialization of tasks (Coleman, 1988; Gargiulo and Benassi, 2000). As a result of this process, close networks exhibit a convergent tendency towards increasingly homogeneous and equilibrium like outcomes (Coleman, 1988; Gargiulo and Benassi, 2000; McPherson et al., 1992). This is consistent with institutional research (e.g. DiMaggio and Powell, 1983).

From an Austrian economic context, closed networks offer the entrepreneur opportunities to identify with similar other entrepreneurs and promote a greater mutual consistency of behaviors. This is because as closed networks connect an entrepreneur to a common body of experiences, proximity to such a common body of experiences enables the entrepreneur to more readily identify the subjective errors or mistakes of others. By identifying with such subjective errors, a close network offers alert opportunities to avoid and improve upon the mistakes of its closed network members. This is consistent with Hayek's (1978) competitive discovery processes in which subjective entrepreneurs build and revise upon local knowledge experiences. This is also consistent with social comparison research that finds firms tend to learn and avoid the mistakes of their local partners. For instance, in Baum and Ingrams' (1998) study of hotels in Manhattan, they observed hotels undertake 'vicarious learning'. With vicarious learning, hotels develop practices that build upon the successful practices of their close competitors, while also improve upon their practices by avoiding their rivals' failing experiences.

However, unlike Coleman (1988), a closed network of subjective and alert entrepreneurs does not converge to a homogeneous and equilibrium like outcome. Rather, 
the convergent pressures of a closed network generate internal pressures for an entrepreneur to develop plans that differentiates itself from its local partners. This is because since subjective and alert entrepreneurship fundamentally resides in the expression and exploitation of an entrepreneur's idiosyncratic knowledge and preferences, an entrepreneur's ability to survival, thus, rests on the entrepreneur's ability to maintain its distinction relative to its rivals (Jacobson, 1992). Hence, as closed networks generate an increasing consistency of expectations and plans, the subjective and alert entrepreneur, in search for less competed opportunities, develops a plan that differentiates itself from that of its rivals. This is consistent with Deephouse's (1999) strategic balance hypothesis in which he found increasing strategic similarity lead to increasing pressures for a firm to seek differentiation. However, unlike Deephouse (1999), such differentiating activities are not sustainable. This is because a close network consists of a dense network of relationships in which such differentiating activities become readily identifiable and thereby imitable by other closed network members. As such differentiating activities are imitated, this induces the subjective and alert entrepreneur to seek other differentiating plans to create another cycle of competitive imitation. As a result, a closed network of subjective and alert entrepreneurs does not converge to an equilibrium state, but rather such a network exhibits an alternating cycle of converging and differentiating behaviors. This market process is hypothesized by the following:

\section{1a) A closed network of subjective and alert entrepreneurs generates a market process characterized by an alternating cycle of strategic similarity and differentiation.}

Despite such an alternation of entrepreneurial behaviors, an 'unintended consequence' of closed networks is they generate 'social norms or rules' (Coleman, 1988; Gargiulo and Benassi, 2000) that promote the development of a 'spontaneous order' (Fleetwood, 1995; Hayek, 1948, 1967). Unlike the concept of equilibrium, a spontaneous social order exhibits a pattern of regularity that is globally stable, but is yet locally unstable (Fleetwood, 1995; Hayek, 1967). Specifically, as a closed network creates incentives for entrepreneurs to differentiate or move away from equilibrating outcomes, such differentiating behaviors introduce new plans or resource combinations. However, not all plans will succeed and, in fact, most will fail. Such failed plans constitute 'social rules' that reflect the collective knowledge of an entrepreneur's local environment (Fleetwood, 1995; Hayek, 1978; Sabooglu and Langlois, 2001). These social rules are a solution to more successful plan attempts because social rules guide or channel an entrepreneur to activities that avoid the repetition of past mistakes (Fleetwood, 1995; Potts, 2001; Sabooglu and Langlois, 2001).

Social rules generate a global order because the avoidance of past failures removes some of the unsuccessful variations introduced by subjective action. By removing such subjective experiences, social rules render a greater consistency or mutually compatibility of plans to which promotes the onset of a market order. In that, by removing such unsuccessful variations, social rules reduce the uncertainty in the actions of the collective (Fleetwood, 1995). This is because social rules enable each entrepreneur to better predict in a general sense what other entrepreneurs 'will not do'. In this fashion, entrepreneurial actions become 'predictable enough' to form plans that are mutually consistent with each other (Lewis and Runde, 2007). Such consistency enables entrepreneurs to better anticipate and coordinate the actions of other closed network members and thus promoting an orderly outcome. Yet, due to the spontaneous and creative influences of an entrepreneur's subjectivity, the specific actions of what each entrepreneur 'will do' cannot be determined precisely. As Hayek (1967: 167) notes, social rules '... merely delimit the range of permissible actions but do not determine the particular actions of a man must take at a particular moment'. As a result, although the diffusion of social rules by a closed network promotes the emergence of a global social order, closed networks, however, cannot converge to final equilibrium state. This is because since social rules do not dictate what an entrepreneur's should do, individuals still have some freedom or 'liberty' to exercise their subjective imaginations (Hayek, 1948, 1967). As result of this subjectivism, the details or the specific entrepreneurial actions of this global order are not predictable (e.g. Hayek, 1978; Kirzner, 1997). Consistent with Hayek (1978) and Kirzner (1997), market processes, thereby, exhibit a tendency to approach, but not reach an equilibrium state. Given hypothesis $1 \mathrm{a}$, the following is, thus hypothesized:

\section{1b) A closed network of subjective and alert entrepreneurs leads to an orderly market outcome.}

Diverse networks. Unlike the constraining and ordering influences of a closed network, a diverse network is a 'structural hole' (Burt, 1992) that yields opportunities from 'brokering' disperse knowledge and information (e.g. Ng, 2004; Perry-Smith and Shalley, 2003; Reagans and Zuckerman, 2001). In particular, since Schumpeterian innovation is a result of a novel recombination of resources (Kirzner, 2000), the brokerage function of a diverse network exposes an individual to new ideas. As diverse networks expose individuals to new experiences, diverse networks promote creativity and innovation (Burt, 1992; Ng, 2004; Perry-Smith and Shalley, 2003; Reagans and Zuckerman, 
2001). This is consistent with empirical studies that find exposure to diverse networks improves a firm's creativity and ability to innovate (e.g. Perry-Smith and Shalley, 2003).

In the context of Austrian entrepreneurship, a diverse network encourages an entrepreneur to 'imagine' new innovations to which such novelty yields a destabilizing influence to the market. As a diverse network exposes an entrepreneur to a breadth of resources and experiences, it provides various opportunities for each entrepreneur to imagine a combination of resources that it believes to be successful. As these subjective imaginations are introduced, new innovations or plans are developed. These new innovations further extend the breadth of experiences of a diverse network to which provides further opportunities for entrepreneurs to imagine other combinations of resources. As a result of this cumulative process, plans become increasing divergent and incompatible because as each entrepreneur introduces their creative imaginations, new innovation are introduced to disrupt or render obsolete earlier innovations. Such a divergence of innovative experiences leads to increasingly incompatible plans (Lewis and Runde, 2007). This incompatibility in turn inhibits the mutual coordination of market activities that is required for socio order (Lachmann, 1977). As a result, since a diverse network yields a proliferation of new innovations, the increasing divergent and thus incompatible plans lead to an increasingly unstable market. The following is, thus, hypothesized:

\section{2a) A diverse network of subjective and alert entrepreneurs leads to a highly unstable market.}

The instability of markets also depends on an entrepreneur's efforts to reveal new resources to its diverse network. Since the subjective entrepreneur reveals 'novelty or surprise' to the market, such novelty arises from an entrepreneur's efforts to experiment with new factors of production or resource components that have not been previously revealed to the market. Such an infusion of novelty introduces the 'ingredients' or resource components that are necessary for the development of new resource combinations. Subsequently, as new innovations are revealed, it introduces new productive relationships that can be later exploited by other alert entrepreneurs to which promote another sequence of innovations. Thus, through the experimental efforts of the entrepreneur, the revelation of new resource components is instrumental to developing new resource combinations - innovations - that generate instable market outcomes. Hence, in drawing on the 'surprise' and 'novelty' generating aspects of alert entrepreneurship, the following is hypothesized: 2b) The greater the innovative experimentations (i.e. introduction of a new resource) conducted by entrepreneurs, the greater the effect of a diverse network in developing new resource combinations.

Entrepreneurs with Closed and Diverse Networks. As market processes are likely to exhibit both closed and diverse network relationships, such a 'joint' or hybrid network can yield a combination of orderly and disorderly market behaviors. Although a closed network of subjective and alert entrepreneurs yields an orderly market outcome, the presence of a diverse network mitigates such order. Due to the presence of a diverse network, such a network introduces novelty or innovations that destabilize the ordering tendencies of a closed network. Conversely, a closed network confines or constrains the novelty generated by diverse networks. This is because the social rules of a closed network dampens or reduces the novelty or innovations created by a diverse network. As a result, under a joint or hybrid network, periods of market order and disorder are likely to arise. The following is hypothesized:

\section{3) A closed and diverse network of subjective and alert entrepreneurs yields 'temporarily' orderly and disorderly market outcomes.}

\section{Method: agent based simulation modeling}

\section{Model setup}

A key facet of agent-based models is they emphasize the interactions of heterogeneous and rule based artificial agents (Lane, 1993). In this study, the heterogeneity of agent behaviors is modeled after the subjective and alert entrepreneur. By drawing on such subjective and alert premises, the agent / entrepreneur does not exhibit the rational behaviors described by neoclassical economics (Kirzner, 1997). Rather, an agent's behavior is governed by heuristics or rules of thumb. In addition, as agent based models emphasize interactions, an agent's interactions are characterized by the exchange of knowledge (i.e. plans) amongst members of a closed and / or diverse network. In developing this agent based model, entrepreneurs / agents occupy in 1 of 3 different product-markets. 3 productmarkets were chosen because it captures the diversity of experiences ascribed by the diverse network concept ${ }^{2}$. With these 3 different product-markets, diverse relationships

\footnotetext{
${ }^{2}$ Although two product markets were considered, a third product market was introduced to encompass a greater diversity of experiences.
} 
are defined by an agent's interactions between members of different product-markets. While, closed networks are defined by an agent's interactions with network members who reside in the same product-market. To distinguish these 3 product-markets, each product-market employs a distinct production technology that requires the use of a specific combination of resources that is not known by the entrepreneurial agents. To reveal this specific combination of resources, entrepreneurial agents draw on their heuristics to reveal a combination of resources that are unique to the requirements of their product-market. In addition, the production technologies of each product-market are independent of the technologies of other product-markets. This means there are no production or network externalities between the product-markets.

Within each of these product-markets, each entrepreneur is initially assigned a random combination of 8 resources. After this initial period, each entrepreneurial agent, then behaves in accordance to 6 decision heuristics or rules, $\theta$. Each heuristic, $\theta$, creates either a closed or diverse network of members (see Table 1). Within this network, the agent formulates a combination of resources (i.e. plans) by learning from the resource choices (i.e. plans) of four other network members. Once an agent has chosen its resource combination, its resource choice then determines its level of output, cost of production and profits. This process is then repeated over multiple periods (300 time steps) in which for every period, the agent can choose a different heuristic, $\theta$, to develop a different network consisting of different members to form a different combination of resources. This generates a different level output, cost and profits. Through this process, the agent over time accumulates new knowledge by

\section{Table 1. An entrepreneur's rule, $\theta$.}

Close network rules:

1. Imitate the most profitable resources from its closed network;

2. Revise upon the most profitable resources from its closed network;

3. Avoid the resources chosen by the most profitable entrepreneur in its closed network.

Diverse network rules:

4. An agent adopts a resource from the most profitable entrepreneur in its diverse network;

5. An agent randomly or innovates a resource that it has not used before;

6. An agent recombines four resources from the most profitable entrepreneur in its diverse network with those of its own. learning from the resource choices of its network members. This follows the decentralized learning processes described by Hayek's (1978) competitive discovery process and departs from the rational premises of neoclassical economics.

\section{Heterogeneous and adaptive agents: entrepreneurial heuristics}

As an agent's decision heuristics are central to agent based models (Lane, 1993), an agent's heuristics, $\theta$, are shown in Table 1 . These rules are classified into 2 categories: close and diverse network rules. For each time period, $t$, each agent chooses a rule from either of these categories. Based on their rule choice, the rule determines an agent's type of network: closed or diverse networks. By emulating the resource choices of its network members, the chosen heuristic then determines an agent's combination of 8 resources (i.e. a plan), as shown by the vector, $X_{t}(\theta)$. In particular, each of these heuristics involves emulating the resources of a network member that the agent perceives to exhibit the greatest profits. This is to capture the notion that the alert entrepreneur learns from successful others so as to seek improvements in their own wealth.

Subjective profits: to determine, an entrepreneur's choice of these 6 rules, $\theta$, an agent chooses the rule that maximizes the agent's perceived or 'subjective profits'. To determine this rule, the agent computes the 'subjective' profits for each rule, $\theta$, with its associated resource combination, $\mathrm{X}_{t, i}(\theta)$, and then chooses the rule that maximizes an entrepreneur's perceived profits.

An agent's 'subjective' profit function is shown in Equation 1. For a given product-market, an agent's subjective profits, $\Pi_{t, i}^{s}\left(\mathrm{X}_{t, i}(\theta) \mid v\right)$ at time, $t$, determines the profits associated with the $i^{\text {th }}$ resource combination specified by the vector $X_{t, i}(\theta)$ whereby this vector of resources is determined by a rule, $\theta$ (Table 1$)$. Subjective profits are determined by the product of an agent's product-market price, $p_{t^{\prime}}$ and its' 'perceived' or subjective output, $y_{t, i}\left(X_{t, i}(\theta) \mid v\right)$. Subjective output is based on an agent's resource combination, $X_{t, i}(\theta)$, in which their productive contributions (i.e. marginal product) is conditioned on the agent's subjective beliefs, $v . v$, is a vector of an entrepreneur's subjective marginal productivities that is associated with its resources, $X_{t, i}(\theta)$. These subjective marginal productivities, $v$, are driven by a random number generator with a range between 0 and 1 . To account for an entrepreneur's hubris or overconfidence (Kirzner, 2000; Russo and Schoemaker, 1992), these subjective marginal productivities, $v$, have an upward bias. For instance, if the random number generator yields a value of 0 , an entrepreneur's subjective marginal productivities equates with a set of true / objective marginal productivities. A value of 0 would indicate that an entrepreneur has 
subjective expectations that correctly anticipated the productive contributions of its resources. As a note, these true / objective marginal productivities are exogenously defined and are not known by the entrepreneur. While, a value of 1 would yield a $40 \%$ increase to an entrepreneur's subjective marginal productivities over that of the true / objective marginal productivities. This indicates the entrepreneur has over estimated or is overconfident in its assessments of its resources' productive contributions. A $40 \%$ value was chosen because it is consistent with values reported in overconfidence research (e.g. Kahneman et al., 1982; Russo and Schoemaker, 1992). Such subjective resources choices are then used to compute an agent's costs. Agent's costs are determined by the product of a vector of input prices, $\bar{r}$, and changes in an agent's resources between adjacent time periods, $\Delta X_{t, i}(\theta)$.

$$
\begin{gathered}
\prod_{t, i}^{s}\left(X_{t, i}(\theta) \mid v\right)=\underset{\theta}{\operatorname{Max}}\left[p_{t} y_{t, i}\left(X_{t, i}(\theta) \mid v\right)-\right. \\
\left.\bar{r} \Delta X_{t, i}(\theta)+\prod_{\tau}\left(X_{t, i}(\theta)\right)\right] \\
y_{t, i}\left(X_{t, i}(\theta) \mid v\right)=v \cdot X_{t, i}(\theta)
\end{gathered}
$$

As an entrepreneur's subjective profits evaluates the profits for a given resource combination, $X_{t, i}(\theta)$, these subjective profits also includes the 'past' profits for this given resource combination, $\Pi_{\tau, i}\left(X_{t, i}(\theta)\right)$. An entrepreneur's past profits, $\Pi_{\tau, i}\left(X_{t, i}(\theta)\right)$ constitutes the mean profits for this $i^{\text {th }}$ resource combination for $\tau=\mathrm{T}-1$ previous periods and is shown in Equation 3.

$$
\Pi_{\tau, i}\left(X_{t, i}(\theta)\right)=\frac{\sum_{t=1}^{\tau=T-1} \Pi_{t, i}\left(X_{t, i}(\theta)\right)}{\sum_{t=1}^{\tau=T-1} F_{t, i}\left(X_{t, i}(\theta)\right)} \frac{\sum_{t=1}^{\tau=T-T-1} F_{t, i}\left(X_{t, i}(\theta)\right)}{\sum_{t=1}^{\tau=256} \sum_{i=1} F_{t, i}\left(X_{t, i}(\theta)\right)}
$$

Equation 3 is the average historical profits associated with this $i^{\text {th }}$ resource combination, $X_{t, i}(\theta)$, and is defined by the ratio of the cumulative profits, earned by this given resource combination to the frequency, $F_{t, i}\left(X_{t, i}(\theta)\right)$, at which this combination has been used for $\tau=\mathrm{T}-1$ prior periods. This ratio is also adjusted by the ratio of the frequency of this resource combination to the frequency of all other resource combinations chosen by the agent in its given productmarket ${ }^{3}$.

Past profits were included into the computation of an entrepreneur's subjective profits because it enables the agent to learn from the mistakes of its social network. That is, an agent's past profits captures the concept of social rules.

\footnotetext{
${ }^{3}$ Since there are eight binary inputs, there are total of 256 possible input / resource combinations or plans
}

To explain, since an entrepreneur's resource combination, $X_{t, i}(\theta)$, is derived from interactions from its social network, reductions in an entrepreneur's past profits, $\prod_{\tau, i}\left(X_{t, i}(\theta)\right)$ with a particular resource combination, $X_{t, i}(\theta)$, reflects a failed plan that was chosen by its network members. With a reduction in the profits of this particular resource combination, $\Pi_{\tau, i}\left(X_{\tau, i}(\theta)\right)$, this reduces an entrepreneur's subjective profits. The associated resource combination, $X_{t, i}(\theta)$, and its associated rule, $\theta$, will, thus, less likely be chosen in the current period. Therefore, by including these past profits, an agent will draw on the past experiences of its network members (i.e. social rules) which enable the agent to avoid repeating their earlier mistakes.

To capture an agent's 'alertness', the concept of a threshold or target (e.g. Cyert and March, 1963) is used. This alertness is shown in Equation 4 which states: declines in an agent's previous 'realized'4 profits, $\Pi_{t-1, i}^{*}\left(X_{t-1, i}(\theta)\right)$ relative to its total average historical profits, $\prod_{\tau^{\prime}}$ (i.e. target) triggers an agent to initiate a search for a new rule, $\theta$.

$\Pi_{t-1, i}^{*}\left(X_{t-1, i}(\theta)\right)<\Pi_{\tau}=\frac{\sum_{t=1}^{\tau=T-1} \sum_{i=1}^{256} \Pi_{t}\left(X_{t-1, i}(\theta)\right)}{\sum_{t=1}^{\tau=T-1} \sum_{i=1}^{256} F_{t, i}\left(X_{t, i}(\theta)\right)}$

Product-market (PM) choice. As there are alert opportunities to be made from entering other markets, agents are permitted to exit their current product-markets and enter other productmarkets. This product market choice is influenced by an agent's current choice of resources, $X_{t, i}(\theta)$. This is because since each product-market is distinct in its use of a specific combination of resources, $\hat{X}_{\mathrm{i}}$ an entrepreneur who employs a high level of such product-market specific resources is more likely to enter that product-market. Furthermore, entrance into a product-market is also dependent on the relative profitability of the different product-markets. An agent is, therefore, more likely to enter a product market if it utilizes resources that are required by that market and if such a product market yields greater profits than others ${ }^{5}$.

\section{Results and discussions}

\section{Simulation experimental design and parameters}

To examine the dynamic effects of each network structure, 3 simulations were examined. Simulation 1 consists of entrepreneurs that only choose closed network rules (rules

\footnotetext{
${ }^{4}$ Realized profits are profits that are computed based on true or objective marginal productivities.

${ }^{5}$ Details on the Mathematica code for this decision rule are available on request.
} 
1, 2 and 3). In simulation 2, entrepreneurs only choose the diverse network rules (rules, 4, 5 and 6). Such an arrangement was conducted such that the ordering and disordering properties of closed and diverse networks can be independently examined. In the $3^{\text {rd }}$ simulation, these restrictions are relaxed; the agent can choose any of the 6 rules. Each of these simulations was populated by 60 agents. Due to the computational intensive nature of agent based models, this population was chosen to conserve on the computational and memory demands of the simulation model. In addition, such a population level was used because further increases in the population of agents did not appreciably affect the model results. Another assumption of this model is that agents are uniformly distributed across the three product-markets. However, after this initial period, agents can enter and exit any product-market. To examine market dynamics, the dynamic behavior of the populations of these three different product-markets was examined. This is because population dynamics have been linked to underlying changes in network structure (Miner et al, 1990). Furthermore, changes in product market populations denote fundamental changes to an entrepreneur's resource choices.

Simulation one: a closed network of subjective and alert entrepreneurs. To examine hypothesis 1a, Figure 1 shows the ratio of the frequency of revision (2) rules to the sum of the frequency of the revision (2) and differentiation (3) rules for product-market 1 . A value of 1 denotes that all chosen closure rules were revision (2) rules and thus denotes a high degree of convergence. While, a value of 0 denotes all rules were differentiation (3) rules and thus reflecting a high degree of divergence. When observed over time, Figure 1 shows the ratio alternates, in most instances, to either of the extreme values of 0 and 1 . These rules are also highly negatively correlated (Pearson correlation coefficient is -0.986). This alternating cycle is consistent with the market processes ascribed in hypothesis 1a.

Despite such extreme fluctuations in rule behaviors, Figure 2 shows at the population level, that this closed network exhibited an orderly outcome. This order is reflected by the stable population dynamics of product market 1 (top line in Figure 2). In fact, despite opportunities for entrepreneurs to enter less competitive markets, such as product markets 2 or 3, all 60 entrepreneurs entered and remained in this product market. Furthermore, despite negative profits - the mean profits was -613 for 300 simulation periods, the population in product market 1 remained stable and highly committed to this product-market. These findings -as well as others that are discussed shortly- support the predictions of Hypothesis $1 \mathrm{~b}$.

Simulation two: divergent networks with subjective and alert entrepreneurs. Figure 3 shows a persistent cycle of disorder whereby entrepreneurs exited one product market (product market 2) to enter another (product market 3 ) for the entire simulation period. This dynamic behavior - as well as findings reported shortly - is consistent with hypothesis 2a. More over, to further examine hypothesis $2 \mathrm{a}$, the disorderly influences of this market is examined by comparing the output variance of this simulation with that of the output variance of the earlier closed network simulation. Since variance in output reflects underlying changes in an agent's resources, it is used as another measure of market disorder.

Specifically, the coefficient of variation in outputs are calculated and compared between simulations 2 and 1 . To calculate the coefficient of variation for each simulation, the total variance in output for the three product-markets is aggregated and divided by the sum of the mean outputs of

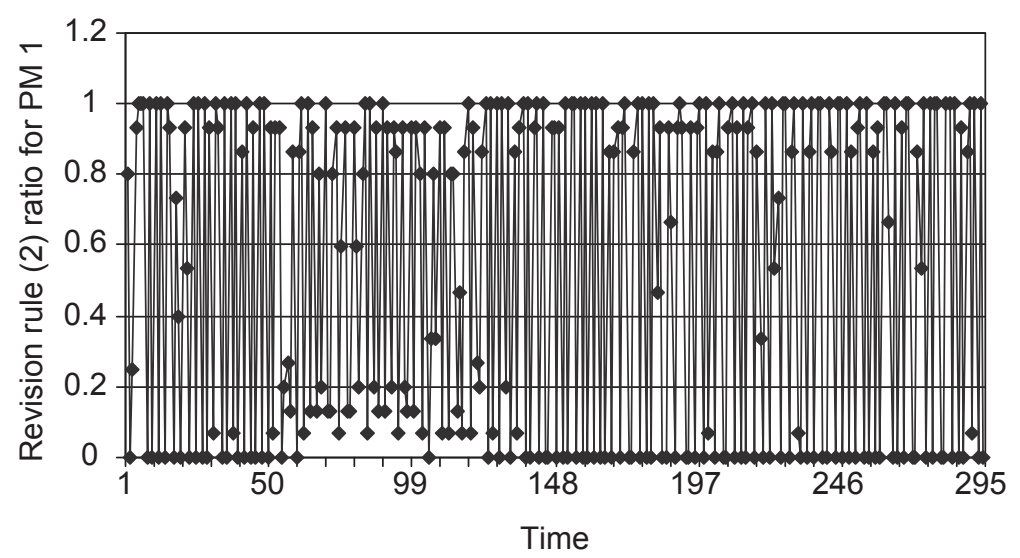

Figure 1. Closed network simulation of the ratio of revision (2) to the sum of the revision (2) and differentiation (3) rules in product market (PM) 1. 


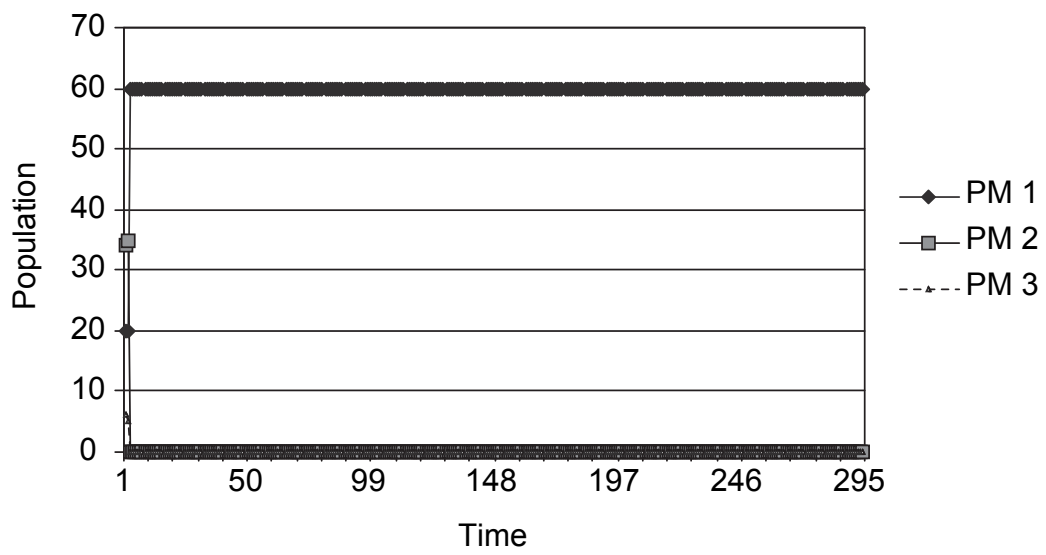

Figure 2. Closed entrepreneurial population.

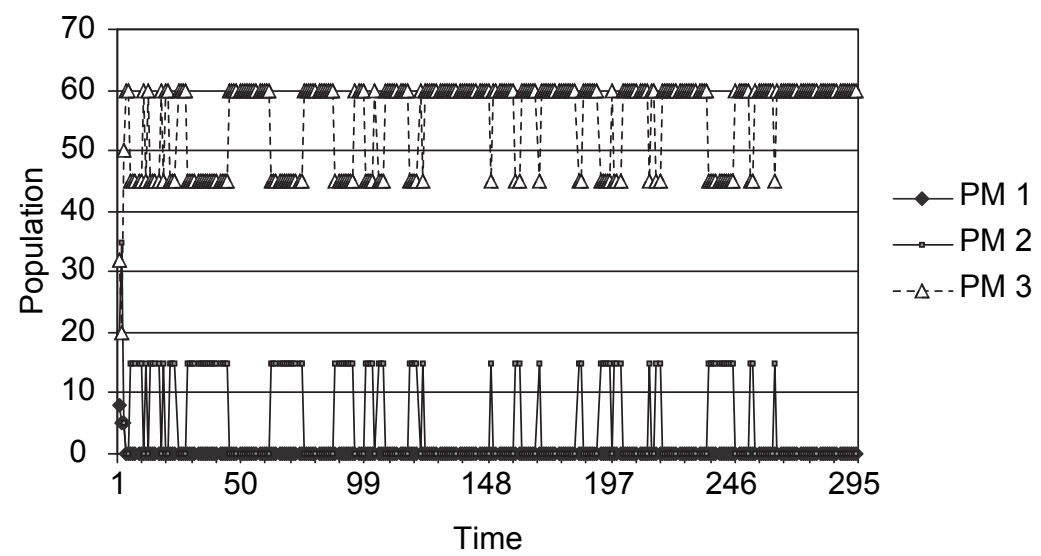

Figure 3. Diverse entrepreneurial population.

each product market ${ }^{6}$. For the diverse and closed network simulations, the coefficient of variation is 1.84 and 1.09, respectively. Furthermore, in using an F-test, the null hypothesis of equal variances between these two simulations was also tested ${ }^{7}$. The F-statistic is 1.69 and is greater than the $\mathrm{F}$ critical value $\left(\mathrm{F}_{\alpha=0.01, \mathrm{df} 1=299, \mathrm{df} 2=299}\right)$ of 1.000 and thus rejects the null of equal variance. Comparison of the coefficients of variation and F-test indicate that a diverse network of subjective and alert entrepreneurs generates greater variation and thus exhibits greater disorder or instability than a closed network. These results support hypotheses $1 \mathrm{~b}$ and $2 \mathrm{a}$.

More over hypothesis $2 \mathrm{~b}$ predicts entrepreneurial experimentations stimulate the recombination of resources

\footnotetext{
${ }^{6}$ Recall, since each of the product-markets has production technologies that are technologically independent of others, the covariance in outputs between markets is zero.

${ }^{7}$ F-test is based on the ratio of the variance in the diverse network simulation to the closed network simulation.
}

in a diverse network. It implies that the greater the frequency with which entrepreneurs experiment with a new resource, the greater the frequency or likelihood that entrepreneurs in a diverse network would choose a recombination rule. To examine this relationship, the Goodman Kruskal (GK test) (1954) associational statistic was used. Its values range from 0 to 1 where a value of 1 means that knowledge of one variable (independent variable) perfectly predicts the occurrence of the other variable (dependent variable). A value of 0 denotes perfect disassociation. To test hypothesis $2 \mathrm{~b}$, the GK asymmetric test tests the directional influence between the pair wise frequencies of the individual innovation rule (i.e. experiment with a new resource) (5) as an independent variable with each of the following diverse network rules: (a) the innovation adoption (4) rule and (b) the innovation recombination rule (6) (dependent variable).

For simulation 2, Table 2 shows the asymmetric GK test statistics for both product-markets 2 and 3 . In both product markets, Table 2 shows the individual innovation rule (i.e. experiment with a new resource component) (5) has a 
significant $(P<1 \%)$ directional association to the innovation recombination (6) and adoption (4) rules. For instance in product market 2, individual innovations (5) are directly associated with the adopt innovation rule (4) with a GK test value of 0.120 . A stronger association was observed in product market 3. However, as shown in Table 2, the directional influence between the individual innovation rule (5) and the innovation recombination rule (6) for both product-markets are substantially greater in magnitude than the pair wise relationships with the adopt innovation rule (4). Hence, an individual's experimentation tends to contribute to a greater recombination of resources than its adoption. These results are consistent with the arguments of hypothesis $2 \mathrm{~b}$.

Simulation three: closed and diverse networks. In this third simulation, entrepreneurs can choose any of the 6 rules shown in Table 1. With this greater choice, both order and disorderly behaviors were observed at different times of market development. As shown in Figure 4, populations changed with less frequency than the diverse network setting (Figure 3), but greater than the ordering behaviors of the closed network setting (Figure 2). The population also exhibited a radical drop in population during period 60 with some further radical changes in periods 160 and 250. Repeated simulation trials were also conducted and yielded a similar pattern of orderly yet disorderly behaviors ${ }^{8}$. Such market behaviors are consistent with hypothesis 3 .

However, to further examine hypothesis 3, repeated simulation trials were conducted. The results of repeated simulations were averaged over 35 independent trials: each differing only in their random seed. These average results did not change with further additions in simulated trials. To compare the order or stability of this hybrid network, a correlation statistic was used to compare the population stability of all three network structures. More precisely, entrepreneurs seek new resource combinations and product market opportunities when their profit performance declines relative to their historical average profits (i.e. Equation 4). Hence, declines in an entrepreneur's current profits create an 'alertness' to seek other product-market opportunities and thereby motivate an agent to exit its current productmarket. Yet, due to differences in the stabilizing behaviors of these different network structures, agents in these networks should exhibit different propensities to exit their current product market. Therefore, to measure the stability or ordering behaviors of each of these network structures, the Pearson correlation statistic between the number of exits

${ }^{8}$ Due to space limitation, the graphical output is not reported but is available on request.

Table 2. Diverse network simulation using the independent variable individual innovation (5).

\begin{tabular}{lll}
\hline Product market / GK asymmetric test statistic & $\begin{array}{l}\text { Dependent variable } \\
\text { (adopt innovation (4)) }\end{array}$ & $\begin{array}{l}\text { Dependent variable } \\
\text { (innovation recombination (6)) }\end{array}$ \\
Product-Market 2 (PM2) & $0.120^{*}$ & $0.466^{*}$ \\
Product-Market 3 (PM3) & $0.225^{*}$ & $0.324^{*}$ \\
\hline
\end{tabular}

${ }^{*}$ Reported values are significant at or below the 0.001 level.

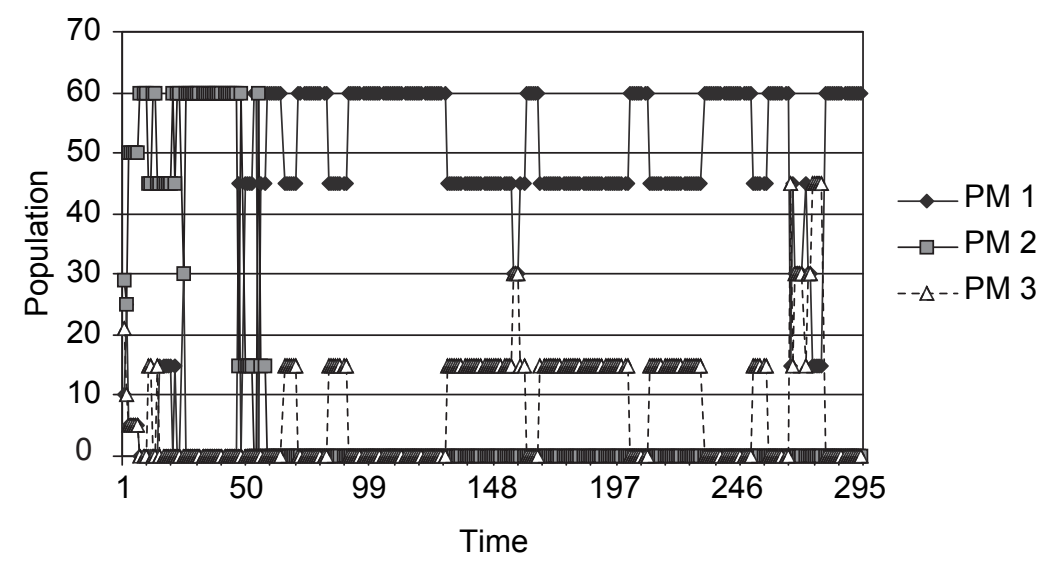

Figure 4. Closed and diverse entrepreneurial populations. 
from a product market (i.e. declines in population in a given product market) and the occurrence of negative or declining profits during this exit period was used. A positive and significant correlation signifies a direct relationship whereby declines in a current product-market population are associated with declines in profit performance for that product market. Table 3 shows the range of Pearson correlation statistics over the three product markets for the 3 different network structures.

Among the 3 different simulations, a diverse network had the strongest and only significant $(P<0.01)$ positive correlation. This indicates declines in the product-market population are directly correlated with declines in the profit performance of that product market. This is consistent with the instable or disorderly market behaviors described by hypothesis $2 \mathrm{a}$. For the closed network structures, their correlations statistics were not significant. This follows the argument that a closed network exhibits an orderly outcome in which its stabilizing behavior is resistant to change. The lack of significance in the closed network findings is consistent with the ordering properties predicted by hypothesis 1a. However, with respect to hypothesis 3, the hybrid network did not exhibit any significant correlations. Relative to the ordering behaviors of closed networks, the stability of the hybrid network does not differ from that of the closed network. Hence, we cannot conclude on the relative stability of this hybrid network with that of the closed network. However, relative to the diverse network, this hybrid network appears to be more stable than the diverse network setting. Hence, relative to a diverse network of subjective and alert entrepreneurs, there is some support for hypothesis 3 .

Entrepreneurial performance of different networks: since alert opportunities are tied to the dynamic behavior of the market (Jacobson, 1992; Kirzner, 1997, 2000), the entrepreneurial profits associated with the 3 different networks are also examined. To compare their performance, the long term average entrepreneurial profits for each simulation is determined by aggregating the entrepreneurial profits over

Table 3. Correlation statistics for product-markets by network structure simulations.

\begin{tabular}{llll}
\hline Simulation Type & $\begin{array}{l}\text { Product } \\
\text { Market 1 }\end{array}$ & $\begin{array}{l}\text { Product } \\
\text { Market 2 }\end{array}$ & $\begin{array}{l}\text { Product } \\
\text { Market 3 }\end{array}$ \\
Closed & 0.177 & 0.120 & -0.186 \\
Closed \&Diverse & 0.146 & 0.018 & 0.168 \\
Diverse & $0.42^{* *}$ & $0.249^{*}$ & $0.249^{*}$ \\
\hline
\end{tabular}

\footnotetext{
* denote significant at the 0.05 level; ${ }^{* *}$ denote significant at the 0.10 level.
}

the 3 product-markets and dividing it by the length of the simulation run (300 time steps). Entrepreneurs with diverse, closed and diverse and closed networks had respective long term mean profits of 33,976 (diverse), 7,405 (close and diverse), and -839 (closed). Mean difference t-tests on the profits for these different networks are significantly different $(P<1 \%)$. This suggests that each network structure yielded distinct market dynamics and distinct performance outcomes.

Specifically, relative to all other network arrangements, a diverse network of subjective and alert entrepreneurs had the greatest market disorder or instability - as has been reported in our previous analyses - and also had the greatest profits. This is because over the long run (i.e. 300 simulation steps), a diverse network of entrepreneurs promotes the experimentation of new resource combinations. Such innovations serve in the discovery of new factors of production and new productive relationships to which increases the profits of this network. A consequence of this experimentation is the diverse network also exhibits the greatest disorder / instability - population and output wise. While, at the other extreme, although a closed network of subjective and alert entrepreneurs promotes ordering behaviors and a specialization of tasks (e.g. Coleman, 1988), entrepreneurial experimentation is significantly confined. In the short run, entrepreneurs may yield gains from 'exploitation' (Levinthal and March, 1993), but in the long run, competition amongst closed network members leads to a decline in returns. Lastly, as expected, the hybrid network - which benefits from both the specialization of closed networks and the innovation advantages of diverse network - yielded an intermediary level of performance.

\section{Conclusions and discussions}

As modern markets of the $21^{\text {st }}$ century have been increasingly described in dynamic and unpredictable terms, understanding market processes and their underlying causes has been the subject of renewed interest. Such interest has garnered considerable attention to Austrian economic explanations of market processes. A central tenet of the Austrian school is that market processes are primarily attributed to the subjective behaviors of entrepreneurs. However, this study argues that the subjective behaviors of entrepreneurs are also determined by the actions of connected others (e.g. O'Driscoll and Rizzo, 1985). As a result, a basic contribution of this study is it extends the methodological individualist premise of the Austrian school to account for the social relationships of subjective human action. By extending the subjective orientation of the Austrian school, this study argues and shows that market processes cannot be examined independently of an 
entrepreneur's social relationships. Such an approach offers three contributions / implications.

First, this study contributes to a basic social problem of how to explain the disequilibrium tendencies that arise from subjective human action while, yet still be able to explain the equilibrative tendencies of socio-economic order (Lewis and Runde, 2007). This study shows subjective human action can simultaneously operate within the context of a socio-order. Namely, the ordering tendencies of a market are the unintended consequences of subjective human action (Hayek, 1978). This was demonstrated in our closed network simulation in which despite the locally unstable behaviors of entrepreneurs (hypothesis 1a), the closed network was globally stable (hypothesis 1b). As a result, in the context of closed networks, this study shows human agency and socio order need not be viewed as mutually exclusive processes. This is because such locally unstable processes generate social rules to which promote the emergence of a global order (Hayek, 1978). This follows Hayek (1978: 184 ) who notes a spontaneous 'order can be preserved through the process of change'. However, in the context of diverse networks, this study shows subjectivism can lead to a continuous state of disorder / instability. Hence, in a diverse network setting, the disequilibrating tendencies of subjectivism and the equilibrative tendencies of social order are mutually exclusive. This is a significant finding because it suggests the type of network impacts the equilibrative (or lack of) tendencies of the market. This finding extends Lachmann's (1977) radical subjectivist view because it shows that market disequilibrium depends on the existence of diverse networks. More generally speaking, as the ordering and disordering tendencies of the market remain a long standing debate amongst Austrian economics, this study's attention to closed and diverse social relationships provides a further consideration of factors that can contribute to the (dis) ordering tendencies of the market.

Second, a basic premise and goal of management is to develop a competitive advantage that is sustainable. Yet the ability to maintain and sustain a firm's long term economic performance is highly dependent on the stability of a firm's market conditions, because when market conditions change, the value premise of a firm's competitive advantage is also changed (Barney, 2002). This study shows that as markets are a dynamic process, the ability for a firm to sustain its competitive advantage is likely an 'illusionary' exercise. For instance, hypothesis $1 \mathrm{a}$ shows that differentiating positions are quickly replicated and imitated. Thus, despite the ordering tendencies of the market (hypothesis $1 b)$, a sustainable competitive position remains difficult to attain. This is consistent with D'Aveni's (1994) notion of hyper-competition. In addition, in more disorderly or instable environments, diverse networks are driven by a high degree of innovative experimentation. In particular, this study shows individual experimentation promotes the development of new innovations (hypothesis $2 b$ ) that displace existing technologies. Hence, our models imply that firms that compete on innovation can create the 'seeds' for their own destruction. To compete in such 'creative destructive' environments (Schumpeter, 1934), a diverse network suggests firms need to not only be able to innovate quickly and earlier than their rivals (i.e. exploit first mover positions), but firms may need to also be able out innovate their latest technological achievements (e.g. Intel).

Third, another related managerial implication of this study is a manager's planning activities maybe conditioned on the social relationships of a market. An important component to managerial decision making is the ability to develop forecasts on matters, such as sales and technology trends. Yet, as forecasting models are typically based on historical data, caution may be exercised in using such approaches, especially in conditions characterized by diverse networks. This is because as diverse networks accentuate the subjective actions of human agency, historical trends do not predict well the spontaneous acts of human imagination (see Lachmann, 1977; Lewis and Runde, 2007). Such an argument draws directly from Austrian's criticisms of the economists' use of historical based methods (Lewis and Runde, 2007). This study, however, offers a more tempered position in which managers who base decisions strictly on forecasting models may need to consider the spontaneous elements of the market process.

There are limitations to this study. From a conceptual standpoint, entrepreneurs are responsive to opportunities from their closed and diverse networks. Yet, this study is agnostic in explaining an entrepreneur's preference for either of these networks. Explaining such preferences would require a greater examination of the entrepreneur's cognitive behaviors, especially with respect to an entrepreneur's risk attitudes towards differences in the spatial and temporal gains associated with these networks. This is called for in future research. Empirically, although this study's agent based model provides some 'initial' results that support this study's conclusions, more extensive examination for their robustness and validation is called for in future research.

\section{References}

Barney, J., 2002. Sustaining Competitive Advantage: $2^{\text {nd }}$ Edition. Addison-Wesley Publishing Company.

Baum, J.A.C. and P. Ingram, 1998. Survival-enhancing learning in the Manhattan Hotel Industry, 1989-1980. Management Science, 44: 996-1016. 
Brass, D.J., J. Galaskiewicz, H.R. Greve and W. Tsai, 2005. Taking stock of networks and organizations: a multi-level perspective. Academy of Management Journal, 47: 795-820.

Burt, R., 1992. Structural Holes: The Social Structure of Competition. Harvard University Press, Cambridge, MA.

Coleman, J.S., 1988. Social in the creation of human capital. American Journal of Sociology, 84: 95-120.

Cyert, R.M. and J.G. March, 1963. A Behavioral theory of the Firm. Prentice-Hall, Englewood Cliffs.

D'Aveni, R.A., 1994. Hypercompetition: Managing the Dynamics of Strategic Maneuvering. Free Press, New York.

Deephouse, D.L., 1999. To be different, or to be the same? It's a question (and theory) of strategic balance. Strategic Management Journal, 20: 147-166.

DiMaggio, P.J. and W.W. Powell, 1983. The iron cage revisited: institutional isomorphism and collective rationality in organizational fields. American Sociological Review, 48: 147160.

Farjoun, M., 2002. Towards an organic perspective on strategy: Strategic Management Journal, 23: 561-594.

Fleetwood, S., 1995. Hayek's Political Economy: The SocioEconomics of Order. Routledge, London.

Gargiulo, M. and M. Benassi, 2000. Trapped in your own net? Network cohesion, structural holes and the adaptation of social capital. Organization Science, 11: 183-196.

Granovetter, M., 1973. The strength of weak ties. American Journal of Sociology, 78: 1360-138.

Granovetter, M., 1985. Economic action and social structure: the problem of embeddedness. American Journal of Sociology, 91: 481-510.

Goodman, L. and W. Kruskal, 1954. Measures of association for cross classification. Journal of the American Statistical Association, 49: 265-268

Hayek, F.A., 1948. Individualism and Economic Order. University of Chicago Press, Chicago.

Hayek, F.A., 1967. Studies in Philosophy, Politics, and Economics. University of Chicago Press, Chicago.

Hayek, F.A., 1978. New Studies in Philosophy, Politics, Economics and the History of Ideas. University of Chicago Press, Chicago.

Jacobson, R., 1992. The 'Austrian' school of strategy. Academy of Management Review, 17: 782-807.

Kahneman, D., P. Slovic and A. Tversky, 1982. Judgment under uncertainty: Heuristics and biases. Cambridge University Press, New York.

Kirzner, I.M., 1997. Entrepreneurial discovery and the competitive market process: an Austrian approach. Journal of Economic Literature, 35: 60-85.

Kirzner, I.M., 2000. The Driving Force of the Market: Essays in Austrian Economics. Routledge, London.

Lane, D.A.., 1993. Artificial worlds and economics, part I. Journal of Evolutionary Economics, 3: 89-107.
Lachmann, L.M., 1976. From Mises to Shackle: an essay on Austrian economics and the Kaleidic society. Journal of Economic Literature, 14: 54-62.

Lachmann, L.M., 1977. Capital, Expectations, and the Market Process: Essays on the Theory of the Market Economy, Kansas City, Kansas, Sheed Andrews and McMeel.

Lachmann, L.M., 1986. The Market as an Economic Process, New York: Basil Blackwell.

Lewis, P. and J. Runde, 2007. Subjectivism, social structure and the possibility of socio-economic order: the case of Ludwig Lachmann. Journal of Economic Behavior and Organization, 62: 167-186.

Levinthal, D.A. and J.G. March, 1993. The myopia of learning. Strategic Management Journal, 14: 95-112.

McPherson, J., P. Popielarz and S. Drobnic, 1992. Social networks and organizational dynamics. American Sociological Review, 57: 153-170.

Miner, A.S, T.L. Amburgey and T.M. Stearns, 1990. Inter organizational linkages and population dynamics: buffering and transformational shields. Administrative Science Quarterly, 35: 689-713.

Ng, D., 2004. The Social Dynamics of Diverse and Closed Networks. Human Systems Management, 23: 111-122.

O'Driscoll, G.P.O. and M.J. Rizzo, 1985. The Economics of Time and Ignorance. Basil Blackwell, Oxford.

Perry-Smith, J. and C. Shalley. 2003. The social side of creativity: a static and dynamic social network perspective. Academy of Management Review, 28: 89-107.

Potts, J., 2001. Knowledge and markets. Journal of Evolutionary Economics, 11: 413-431.

Reagans, R. and E. Zuckerman, 2001. Networks, diversity, and productivity: the social capital of corporate R\&D teams. Organization Science, 12: 502-517.

Russo, J.E. and J.H.P. Schoemaker, 1992. Managing overconfidence. MIT Sloan Management Review, 33: 7-17.

Sabooglu, M. and R.N. Langlois, 2001. Knowledge and meliorism in the evolutionary theory of F.A. Hayek. In: K. Dopfer (Ed.) Evolutionary Economics: Program and Scope. Kluwer Academic Publishers, Dordrecht, 231-251.

Schumpeter, J.A., 1934. The Theory of Economic Development (R. Opic Trans.). Harvard University Press, Cambridge.

Von Mises, L., 1949. Human action: a treatise on economics, $3^{\text {rd }} \mathrm{ed}$. Contemporary Books Inc (reprinted in 1966), Chicago. 